\title{
Connecting Bourdieu, Winnicott, and Honneth: Understanding the experiences of non-traditional learners through an interdisciplinary lens
}

\author{
LINDEN WEST ${ }^{1}$, TED FLEMING ${ }^{2}$ AND FERGAL FINNEGAN ${ }^{2}$ \\ ${ }^{1}$ Canterbury Christ Church University, England and ${ }^{2}$ National University of Ireland, \\ Maynooth
}

\begin{abstract}
This paper connects Bourdieu's concepts of habitus, dispositions and capital with a psychosocial analysis of how Winnicott's psychoanalysis and Honneth's recognition theory can be of importance in understanding how and why non-traditional students remain in higher education. Understanding power relations in an interdisciplinary way makes connections - by highlighting intersubjectivity - between external social structures and subjective experiences in a biographical study of how non-traditional learner identities may be transformed through higher education in England and the Republic of Ireland.
\end{abstract}

\section{Introduction}

In this paper, we connect the work of Bourdieu and his sociological understanding of student experience and social reproduction in higher education - in particular his notions of habitus, disposition and capital - with what is a more interdisciplinary, psychosocial analysis of the place of recognition and selfhood in human interaction, as a basis for transformational processes. We draw, especially, on the ideas of the psychoanalyst Winnicott alongside critical theorist Honneth in interpreting the narratives of 'non-traditional learners' in higher education. These narratives were generated as part of a European Union-financed research study in seven EU countries (RANLHE, 2011). We worked with samples of students and staff from different types of universities in each country. In the UK these were 'older' universities and also 'new' post-1992 institutions, whereas in Ireland they 
include one elite university and an institute of technology with an explicit mandate to address community and economic needs in an under-developed urban area. Despite slightly different systems of higher education, and distinct cultures within universities and the wider societies, there are patterns in the research that transcend national frames of reference. The term 'non-traditional' encompassed students from backgrounds normally under-represented in universities: minority communities and/or working class families, migrant populations and disabled groups. The research included both younger and 'mature' learners. For present purposes, we focus on students who were interviewed, using auto/biographical narrative research, at the beginning, in the middle and towards the end of three years at university. The basic question was what enabled such learners to keep on keeping on at university - or not - understood in the dynamic interplay of past and present, structure and agency, as evidenced through changing narratives.

Bourdieu (1990: 108) made the analogy of students being 'fish in or out of water' and referred to misrecognition deriving from being a fish out of water (Fuller, 2009: 138) in the varying habitus of different universities. Some fish out of water survive and thrive; however, others do not, especially those without particular forms of social and educational capital, shaped by class backgrounds (Reay, David \& Ball, 2005). We wanted to understand this phenomenon in greater depth and wondered if we could provide more holistic, interdisciplinary psychosocial understanding than Bourdieu offers. Learners can, for instance, be considered as potentially more agentic in their social interactions at university, and notions of capital might be broadened to include psychological and familial dimensions. These might encompass, in the case of older learners, resilience forged in diverse forms of lifelong learning, such as surviving various life crises like divorce or unemployment. In building more dynamic, agentic understanding (while recognising the continuing power and pervasiveness of social reproduction processes), Bourdieu's (1986: 241-258) ideas on embodied cultures - of how we internalise a range of norms, including how to think and physically how to relate to others in our dispositions - are connected to Winnicott's concept of changing experiences of selfhood, in transitional space, and how we may develop more open, less defended orientations to experience. The focus is on the complex process of negotiating who we are - an established focus in biographical narrative enquiry - and the resources we draw on in experimenting with self and ways of being in the world (West, 1996). In developing this focus, we drew too on Honneth's concept of recognition and its fundamental place in human well-being: encompassing micro-, mezzo- and macro-level interactions.

In making clear the theoretical rationale for the study, our interest in widening participation and studying the experience of non-traditional students is based on a concern for the development of a more egalitarian and inclusive society, achieved, at least partly, through the possibilities offered by education. However, education has the potential to reproduce inequalities (Bowles and Gintis, 1976) and there is evidence that both inequality and advantage endure through higher education (Murphy and Fleming, 2013). In the RANLHE (2011) research, we sought to chronicle and theorise the lived, embodied, affective, relational and cognitive experiences of students and how these might change, drawing on and integrating these differing but potentially overlapping sensitising concepts (Brown and Murphy, 2012). 


\section{Some background}

Working on the RANLHE study raised difficult questions of how to conceptualise non-traditional learners in universities and how to make sense of adaptation, change, transitional and transformative processes. Notions of transformative learning, for instance - of profound changes in perspectives among learners - are often conceptualised in overly cognitivist terms, as shifts in mental frames or modes of understanding, reflecting the dominance of a sort of disembodied cognition in theorising learning (Dirkx, Mezirow and Cranton, 2006; Illeris, 2002). We can easily neglect the embodied and felt - as well as unconscious and relational - aspects of transitional processes (West, 2011a). At the heart of Mezirow's ideas, for instance (Mezirow et al., 2000), is a metacognitive application of critical thinking. Critical thinking transforms an acquired frame of reference with potentially radical consequences. Critical rationality involves an old mindset being replaced by a different world view. While any mindset consists of values, beliefs and feelings as well as concepts, transformation has to do with changing epistemic assumptions. Dirkx et al. (2006) argue that this can be worryingly reductionist and take the debate about transformative learning into the deeper embodied territory of the search for meaning, even for self and soul. It is persons in relationship that lie at the heart of epistemic shifts. Dirkx et al. seek to understand changes in cognition, but rooted in shifting experiences of self in relation, which could include bodies of knowledge. In earlier work on diverse learners managing change, using auto/biographical narrative research, we have chronicled how people can, in educational contexts, ask fundamental questions of self, engaging feelings as well as thoughts, and how new forms of relationship, including with other learners but also the symbolic order, can be developed. Students may find new narrative resources in the symbolic, which can change their experiences of self (West, 1996, 2009).

\section{An auto/biographical imagination}

In the RANLHE project, we encouraged learners to tell stories as openly and honestly as they could. Learners engaged reflexively in relation to their material, identifying themes and thinking about them with the researchers. There were different methodological assumptions at work among different teams of researchers, despite a common 'biographical research' label. One set of assumptions could be categorised as more 'scientistic' and objectivist, while another was more relational and auto/biographical. In the former, efforts are made to minimise the presence of the researcher, to help build greater reliability in generating interviews; in the latter, the researcher's presence is seen as a potential resource in creating good enough space, in Winnicott's language, for more open and exploratory forms of storytelling (West, 2011b). In our work - in both Maynooth and Canterbury - emphasis is given to attentiveness, respectfulness and the need to take time with the other, to build a relationship of trust; as well as to the necessity to manage anxiety and build secure, collaborative space for storytelling and interpretative work. This includes focusing on the emotional qualities of the relationship between researcher and subject, as part of making sense of narrative material (Merrill and West, 2009). Participants were involved in the analysis of their material via recordings and transcripts; given the longitudinal design, this included 
thinking about what is difficult to say and/or may be missing from the account. This is biographical research in a more clinical style (Merrill and West, 2009; West, 1996, 2009) that may mirror characteristics of psychoanalytic sessions and is proving fruitful in psychosocial research (Bainbridge and West, 2012). Such methods convincingly illuminate struggles to change and moments of transformation as well as the complex interplay of desire and resistance, culture and psyche, in significant learning.

Analytically, in West's work, a proforma is used to identify themes as well as to consider the quality of the process, including the transference (what the researcher may represent, unconsciously, to the interviewee) and the countertransference, which relates to what this may evoke, in turn, in the researcher (sometimes described as auto/biographical dynamics). These processes can be a source of rich insight into the meanings and emotions being communicated (Merrill and West, 2009). Each proforma develops over time and consists of standard biographical data, emerging themes and reference to relevant literatures, in addition to reflection on what might be happening in the relationship we call research. There is immersion in recordings and transcripts, and space given to the emergence of any potential gestalt or overall pattern in the material. This, in turn, helps to make better sense of the detail. This is a different approach to grounded theory, for instance, and the Irish partners were nearer to conventional grounded theory in data analysis. The Canterbury researchers each separately completed a proforma and then compared and contrasted their interpretations, as well as what was illusive and or difficult to understand. The Maynooth data was analysed following the procedures of Charmaz (2006) who proposes a systematic and structured methodology for grounded theory. Her approach involves a careful, reflexive approach to data analysis, through coding and memo writing as well as engagements with literature and other sources of sensitising concepts. This aims to overcome the impression from traditional grounded theory (Glaser and Strauss, 1967) that the researcher allows theories to emerge from the data without foregrounding the researcher's pre-existing epistemological stance.

\section{Sensitising concepts: Bourdieu}

Bourdieu, as indicated, provides a social reproduction frame for considering learner narratives. His work encompasses the concept of habitus, which represents a kind of embodied culture where ideas, practices and ways of being in the world are in play. Such cultures shape how people behave, speak, think and communicate one with another, and even how they deport themselves, chronicled, for example, in ethnographic studies of doctors and the medical training habitus (Sinclair, 1997). Bourdieu's ideas about forms of capital and the ways they operate in specific fields offer a tool for understanding the enduring impact of social inequality in students' lives. Stories are clearly informed by lived experiences of social power. Bourdieu's associated notion of disposition carries the sense that people have internalised an idea of what is expected of them in a particular habitus; in a particular kind of university, for instance. They will be more or less confident with the rituals of communication and language, including what is expected of them in writing, presentation and assessment; and even in deportment in seminars or a range of professional practice-based settings. These expectations and ways of 
being may, for some, have been unconsciously internalised in previous education, while the cultures of particular middle class homes may be closer to the habitus of specific universities. People may understand intuitively what is expected of them, or what counts as academic writing or discussion, for example; or how to engage in the diverse rituals that university may involve - including informal rites of passage or ways of managing anxiety. Mature working class students can struggle in certain universities because their social and educational 'capital' may be somewhat removed from what is valued, understood or practised in a new habitus. This can include the way people speak, or what they bring by way of informal capital, such as adult learning, which may be different from the norm and can go unrecognised. They become, in effect, 'fish out of water' (Bourdieu, 1990: 108).

However, Chapman Hoult (2012) has critically observed that Bourdieu fails sufficiently to engage with how some students with apparently limited educational and social capital nonetheless survive and prosper; how they become fish in water, even in what appears to be a culturally exclusive habitus of elite institutions. Of course, Bourdieu was well aware of this phenomenon and argued, structurally, that such learners serve to mask systemic inequalities - in institutional arguments of 'look, we are open to all the talents!' - yet he fails to engage with the subjective experience of objective possibilities among specific learners who may buck the trend and prosper (Bourdieu, 1988; Chapman Hoult, 2012). It may be the case that Bourdieu's view of capital is too constrained - neglecting psychological or experiential capital (such as lifelong learning) - because his gaze is overly sociological. We need, it is suggested, more fine-grained, psychosocial analysis of how inner worlds may shape outer worlds.

\section{Winnicott and Honneth}

Donald Winnicott (1971) provides one approach to engaging with the subjective experience of objective possibilities. Winnicott meticulously observed and theorised the qualities of relationships in which infants were embedded and the interplay of objective and subjective worlds, self and other. He was initially concerned with transitional processes in early experience: how a child psychologically separates from a prime caregiver, in healthy ways, moving developmentally towards greater individuation as well as psychological integration. He placed the capacity for play and creativity, within the context of 'good enough' relationships, at the core of healthy development, where the child could let go and absorb him/herself in the moment and not be overly preoccupied with what a prime caregiver may think or fearful of their response, which includes anxiety about being abandoned. Winnicott argued that earliest relationships of recognition provide templates for life: good enough relationships, in which the putative self feels sufficiently loved and secure, provide a means simply to be, and a sense of the world as satisfying, where desires may be expressed and fulfilled, including in the transitional space we call play. Less satisfactory relationships can evoke false or compliant responses - a need to appease or please, for instance, for fear of not being good enough or acceptable in the eyes of the other. An obsession with pleasing others and doing what they might want can find expression in later experiences in education; for example, in relationships with teachers and professors in the seminar room (West, 1996). 
Winnicott (1971) insisted that these ideas could be applied to adult development; particular writers have used his concept of transitional space, for example, when thinking of storytelling as a kind of transitional activity, a process of self negotiation, more or less productive of selfhood (Sclater, 2004). We can think of university as a space where self and story are in negotiation and where struggles around separation and individuation - letting go of past ideas and relationships can take place. Like the child, an adult, or rather the infant and child in the adult, may be riddled with anxiety about his/her capacity to cope, or whether he/she can be good enough in the eyes of significant others. He/she may cling to an existing identity, or be overly preoccupied with what others think, or with getting it right for a teacher, which can denude learning and creativity of emotional vibrancy. Learning may be experientially and relationally deadened in consequence. The stories people tell - including to researchers - may, on the other hand, become vehicles for self-renegotiation, for a kind of narrative embodiment of selfhood, which may be more or less legitimised in the eyes and responses of important others.

Honneth (2009) re-visited Freud's work and critiqued a contemporary trend to move away from any imperative to understand ourselves by reference to a deep engagement with our past and proposes, instead, that psychoanalysis makes an important link between freedom and biographical work (pp. 127-128). Autobiographical work involves an ability through reflexive activity to overcome 'the rupturedness of each individual' and 'only by a critical appropriation of her own process of formation does the human seize the opportunity provided to her for freedom of will' (p. 127). In asking how freedom is attainable at all, Honneth asserts that we can re-appropriate our own will by means of recollective work. For Freud, according to Honneth, the individual is 'less a self-interpreting being than one who critically scrutinises its own past to see whether traces of compulsions that have remained unconscious can be found in it' (2009: 139). As the desire for freedom resides within, we can turn to our life histories as valid expressions of our possibilities as humans. In his remarkable departure from Marxism in general and most of early critical theory and even, to some extent, from Habermas, Honneth attempts to reimagine the emancipatory project of critical social theory. His solution is to forefront a theory of intersubjectivity and the 'struggle for recognition' (1995a).

It is interesting that Honneth (1995a: 98) draws directly on Winnicott in theorising how basic self-confidence is facilitated: in the attentiveness and legitimacy in short, the recognition - provided by the other. In attending to the experiences of students in the context of their relationships, Honneth provides a normative grounding upon which a new iteration of critical theory can be built, which connects ordinary human experiences and concerns about identity with more social struggles against exclusions. In attending to the detail in students' biographies we can understand their struggle for recognition through higher education. This is an insight into the individual and shared needs of people. This approach has only recently taken a foothold in educational theory and practice (Brown and Murphy, 2012; Fleming, 2011; Huttunen, 2008; Murphy and Brown, 2012).

Honneth's theory of recognition offers a 'link between the social causes of widespread feelings of injustice and the normative objectives of emancipatory movements' (Honneth in Fraser and Honneth, 2003: 113). In short, in the research 
project, any theoretical or analytical framework was only useful if it allowed us to connect the psychological and social dimensions of human experience. Honneth provides a psychosocial perspective on identity formation that depends on interpersonal relations and recognises personal experience. Only by being recognised can we achieve an identity and become conscious of our own uniqueness. There are clear links here with Bowlby as well as Winnicott (Honneth, 1995a: 97) and the links with the psychological dimension reach back to Fromm and Marcuse. Honneth reconstructs and reclaims these and argues (1995a, 2007, 2009) that critical theory concerns itself with everyday experience. As fundamentally intersubjective beings, processes of recognition underpin both our personal and social development. According to Honneth:

... the reproduction of social life is governed by the imperative of mutual recognition, because one can develop a practical relation-to-self only when one has learned to view oneself, from the normative perspective of one's partners in interaction, as their social addressee. (Honneth, 1995a: 92)

By attending to individual experiences as well as to people's moral intuitions and concerns we can discover the concerns and struggles that make important disclosures about collective human needs and also about social power (Honneth, 2007). Recognition, in Honneth's view, is simultaneously an individual and a wider socio-cultural phenomenon. He (1995b) argues that there are three differentiated recognition orders in modern society, the development of which are crucial to understanding the dynamics and historical evolution of capitalism and modernity; each order is defined by different forms of recognition needs and expectations. The first order requires love in the family or interpersonal sphere for the child to develop self-confidence. In Honneth's schema, this leads to self-confidence, born in relationships of love and of being seen and valued at a basic level. If one experiences love, an ability to love oneself and others is developed. An identity (or selfhood) is being forged by receiving recognition from others. Only by being recognised can we achieve an identity.

The second type of relationship to self has to do with self-respect, when a person belongs to a community of rights and is recognized as a legally mature person (Honneth, 1995a: 129). Recognition of the autonomous person, bearing rights in law, is the basis for self-respect. Through this comes the ability to participate in the discussions and rituals of the institution concerned. Respect is shown to others by acknowledging their rights. Without rights there is no respect, to put it slightly differently. It is not just having a good opinion of self but a sense of possessing a kind of shared dignity of persons as morally responsible agents and as capable of participating in public deliberations.

The experience of being honoured by a community for contributions leads to the third form of self-relation, which Honneth terms self-esteem. People with high self-esteem will reciprocate a mutual acknowledgement of each other's contribution to the community (Honneth, 2007: 256). From this grow loyalty and greater social solidarity (p. 139). As the family is considered to be an appropriate location for the first form of relating to self, schools may be a good example of institutions that play a role in recognising rights and developing self-respect. But, more importantly, higher education is seen by many of those interviewed as an important location for this third form of relating to self; yet it also encompasses 
the other two dimensions, including meeting quite basic needs to feel seen and recognised.

It is not surprising to have three corresponding forms of disrespect (Honneth, 1995b: 249). Neglect, abuse and humiliation of children may lead to a loss of selfconfidence and self-esteem may be damaged by disrespect among adults and the denial of rights (bullying, etc.). Damage may be done in these ways to peoples' understanding of self and their identity (Honneth, 1995a: 131). If we have become accustomed to thinking that the personal is political, this adds the possibility that the political may also be personal.

This research moved beyond traditional Marxist approaches of political economy (Marx) and deliberative democracy and will formation (Habermas), in an attempt to engage with what these traditions could not: resilience, personal identity development and struggles for recognition and selfhood. Theories of resistance do not help us understand how and why so many students interviewed see higher education as a space that helps remedy the mistreatments and disappointments of an unequal society and school system. Thus a different set of ideas was developed: a repertoire that would explain why so many students anticipate and experience higher education as a space in which they can claim a sense of self, enhance their self-confidence, boost their self-esteem and remedy previous misrecognitions. Honneth (1995a: 92) allows us to understand more of these highly nuanced processes.

\section{Cases in point}

We draw on the narratives of particular non-traditional learners from the RANLHE research who help illuminate these ideas in particularly 'telling' ways. These are cases revealing common themes across a number of biographies in acute and or complex ways (West, 1996). They are typical of the narratives told and heard. Adults often frame their narratives of returning to education by reference to increased self-confidence - however fragile at times - and these experiences of increased self-confidence have not been theorised in this way to date. University, however, can be a problematic habitus for working class students; yet becoming more of a fish in water is possible. Self-confidence can be enhanced (perhaps, more fundamentally, experiences of selfhood strengthened, as Winnicott would have understood it) through acceptance by lecturers and significant others: producing the feeling that we can play in this space - the world of ideas, for instance and feel accepted and legitimate in doing so. Self-respect may be forged because of feeling accepted as part of a community of rights; of being a student with a status and the competence to give as well as receive. Self-esteem may be the outcome of feeling honoured in a university and, perhaps, in a broader community. This might include success in the practical rituals of professional placements or in advocacy as part of a legal training; or by acting as a legal adviser in ways considered crucial and fulsomely recognised by marginalised clients.

Honneth (1995a: 163) implies that such a pursuit serves as a process of identity development. The way in which this is facilitated indicates a profound social dimension, as a society or a community - through the validation and qualification of higher education, for example - acknowledges and respects the individual in ways that issue in increased social solidarity and reciprocity. The tantalising 
possibility is presented that self-confidence, self-respect and self-esteem, or rather the environments in which these forms of respect are created and enhanced, become the habitus, at least in part, contributing to successful participation and retention in higher education. The fact that the habitus is a fluid, dynamic, psychosocial construct may be a new way of seeing how and why students 'keep on keeping on'.

\section{Meet Sue}

Take the case of someone we call Sue, a working class student in an elite university law faculty, somewhere near the pinnacle of esteem in higher education, at least in terms of Bourdieu's framing of the French academy of the 1960s (Bourdieu, 1988). Sue was a serious and passionate student of Law. Divorced with two children, she had lived for a while on welfare benefits and had been a carer for her father till his death. She returned to a childhood ambition to practice law. Her biography embodies determination to overcome difficulties, which include poverty and emotional vulnerability. She persevered with the challenge of learning in higher education. Whilst deeply disturbed by class and its manifestations in the academy, she can be seen as resilient. We noted with interest that issues of gender were relatively unimportant to her; rather it was class that troubled her. She looked for recognition in the academy, feeling awkward in lectures and in the world of the London Inns of Court, where students were expected to spend some of their time.

In her first interview, she said:

I mean it's getting used to... the gap with the education you know it's so different going back into that environment you know comparing with younger students, you know, but it's a natural progression for them and they're up to speed with everything ... well I would need to complete my degree and do the bar... a year at bar school...I don't doubt I will do it, I don't doubt myself, I really don't. I worry about how good I will be ... sorry ... [upset]

She talked of her relative 'lack of education' and constantly asked in seminars what words meant. She said she had learned 'the confidence to speak up and say oh what's that then ... and I'll look it up later'. She talked of different types and styles of lecturers: some easy to listen to, others humorous and some very serious:

That's really a bit tricky, so I don't want to be spoon fed the information but the same times you've got to bit the ground running with it...

Sue talked at length about her background: the law was 'just part of your everyday life' in a working class area of London, where arrests and even murder, as she put it, were frequent companions. She also mentioned feeling an outsider in the community, at times, of 'not wanting to push buggies down the High Street':

You know I wanted to make something of my life and always believed that you could do whatever you wanted to do, and ... that that wasn't all there was, you know, there was a lot more to it than that and you could bring up children and have children and ideally you know in a situation where you've got a husband or stuff like that and if it doesn't work out like that then you just get up and get on with it but it was never going to stop me from doing what I wanted to do, be a success in my own business or, you know, to do this, what I wanted to do since I was about 11 years old. 
Sue agonised, once at university, about moving between the different cultures (or habitus) of the university and the street and about what others might think of her. Negotiating the space was hard, for example:

I've really agonised over the way I speak and stuff I think, you know I'm just not going to be able to speak how I would wish to speak and I've got to be comfortable with that and if I make slips so be it I've got to say this is me and here we go... but it sounds really naive but I didn't know how a university worked, I really never and I just sort of ob right, this is what you do because nobody has ever been to university. I had never spoken to anyone about a university and none of my family has ever been so I had no idea what it was going to be. It is a shock.

In the classroom, accent could be equated, she said painfully, with very negative qualities:

...to ignorance and bad manners and you know all of that and lack of intelligence... I've got to understand that it is natural and just think and overcome that with my own abilities. It's like an inner turmoil, almost every walk of life comes with prejudice and you know discrimination and I put it akin to racial discrimination, it's no different really from social discrimination you know but that's not recognised, it doesn't really...

She had been fearful of 'messing it up and then you've humiliated yourself because you've pretended to be something you're not...'. She was, she said, past trying to speak in a particular way; and if she changed, 'then I would have all my family ridicule me'. Moreover, she thought of the law as a 'kind of close knit community', a space that was difficult to enter. In a second and third interview, Sue talked more of her dad and his heroic struggles against legal authorities, including the police. He was, she said, an important influence, inspiration even, whose struggle continued to inspire her against injustice. She had been a successful business woman too, underlining the danger of reducing Sue simply to deficit capital status. She had begun to subscribe to The Times newspaper (with its extensive daily law reports). She talked positively of her experiences in some of the practical rituals of the legal training, of being a trainee advocate in a mock court, and representing marginalized people:

... I got involved in a lot of university like mooting, I became a mooting officer... They call it a mock trial but it's not, it's at appeal level so it's a mock appeal... that's really interesting... and I volunteered in the law clinic which has been really good which I actually won an award... and you know you do get I mean when I've been in many courts and listened to advocates and you get sort of international words of English together. So I think well never mind I can't speak English but neither can you ... But in a courtroom I've always felt more comfortable for some strange reason which goes against anything I'd normally feel... [laughing] ...

Sue was highly commended in representing a client by a magistrate in a mock process and this experience, including being a mooting officer alongside providing free legal advice in a law clinic, contrasted with her continuing struggle to feel at home and herself in other rituals. She went to an end-of-term party, for example, at the Inns of Court in London and felt out of place with the rich and privileged young people and their behaviours. Yet she also felt valued by some of her tutors and able to invest in the practical rituals of the moot and to represent 
marginalised clients. Self-confidence (investing in selfhood, in Winnicott's terms), self-respect (because of feeling accepted as part of a community of rights, not least through her own agency) but also self-esteem (legitimacy in a wider academic and legal community) were developing 'psychosocially'. In part, with others, she was creating a different quality of habitus.

Sue remained both vulnerable and simultaneously tough, having survived difficult circumstances, including a divorce. Her psychological capital, not least forged in adult learning and success in an Access programme, was strong yet vulnerable when negotiating the classed habitus of the Inns of Court. She was no feminist or socialist, she said - values often promulgated by members of the law faculty (which had a radical reputation) - but she felt deeply about injustice and did particular rituals well. She was managing the transition reasonably successfully and the resources drawn on included some of her teachers; she felt recognised and thus able to play with new possibilities. Recognition encompassed stronger feelings of self - in the play of advocacy - but also growing self-respect because of being seen as competent (despite continuing feelings of being the outsider); and there was self-esteem forged in being recognised in a wider legal world, and among specific clients. They made her aware of what she could bring to the law and that she could be a valued member of that community in the process.

\section{Meet Katy}

Katy is in her 30 s and a student at a non-elite Irish university. She is bright, reflective and forthcoming and proved to be a fluent and engaging interviewee. Each time we met with Katy it was clear that she had thought through many of the things we discussed in the interview in great detail and in depth beforehand. From early in the research process she was candid about her life and learning experiences. She analysed the institutional and pedagogical organisation of the course in which she was enrolled in a sophisticated way. Katy grew up in Dublin and lived with her parents in a cottage with ample room on a green space nearby for play. Her parents both worked, until her father was made redundant in Katy's late teens. This left the family struggling financially. The family was close but also 'hectic' and at times 'turbulent'.

In the interviews with Katy she returned to the subject of schooling quite often: 'I always refer to myself as the person who fell through the cracks...in school'. Despite finishing her Leaving Certificate she slowly internalised the idea that she 'was stupid' and though she may have suspected that this was not completely true it became an important part of her self-understanding as a learner and person. She did not speak angrily about this but maintained a sense of it being unjust and linked to social class. Her story illustrates how institutions, the interventions of individual teachers and structural inequalities play out in learning stories that are frequently accounts of disrespect. She remembers a teacher saying to her mother:

'It doesn't matter if she doesn't pass the class she is just going to end up in a job anyway. She'll never get to college.'

So I felt then that was the perception of someone who was over me. He was a teacher and he was intelligent and powerful. He was telling my mum, 'Don't worry if she doesn't get it, she never will...' 
[She began to think that] this is who I am. I am not meant to be in college. So from that moment on I didn't apply myself.

At home there was not much support; her mother was intellectually curious yet had been 'held back' by circumstances - the demands of rearing a family and the gendered expectations of her era. As a result, Katy left school unsure of her options and with a sense of being an underachiever. It appears from other things she says that this negative learner identity was not the whole story and her estimation of herself was more complex and multilayered than the judgements made by teachers. Katy suspected that she had capabilities that were not being tapped but nonetheless the dominant story remained that she was 'stupid'.

After school she worked in shops and then applied for a Further Education course 'But it wasn't really college' to her mind. She eventually got work in a transnational corporation and became a capable and trusted member of staff. However, within a few years she had reached a point beyond which she could not have been promoted without a degree. Frustratingly, other people with less experience and who had spent less time in the company were promoted ahead of her. She was 'respected' at work but she was still concerned about her capability as a learner. She wanted work that matched her deeper concerns and interests. She decided 'I wanted to go back [to education] for my own self-esteem to try to see can I do this'.

Three other things made her desire to return to learning a possibility. Firstly, Katy's company decided to relocate to Asia. 'I was made redundant,' she says and, in slightly surreal twist in how the movements of global capital has an impact on lives, Katy found herself taking part in this process by being asked to travel to the new site in Asia and help train the workers there for their jobs. Secondly, the financial cost of returning to college was eased. She got assistance on the Government scheme that made it possible to return to education on becoming unemployed. Thirdly, her care responsibilities for other family members eased.

Katy is emphatic that her decision to go to college was not motivated by a desire for more money but greater choice in work and a job that was closer to her own interests and desires. Even more emphatically, she links coming to college with self-esteem and undoing the impact of disrespect and low expectations. A sense of how she construes her choices in this way can be gathered from the following exchange. Katy was discussing her future plans for work after her course:

\section{I would love the idea of helping and teaching.}

Asked why, she responds:

Because I wasn't helped. No one recognised any potential in me. You see these inspirational movies. Like a basketball coach comes in and inspires the kids to become scholars. I always had aspirations to do well, but at the time my family life wasn't built in such a way that I was getting that from my home life. But I would have loved a teacher or someone to recognise potential in me. But no one recognised the potential ever. I have aspirations of helping in such a way of recognising in others the reasons they are not achieving ... That I would be someone who would recognise and realise there is a different way.

As Katy has progressed through college she has become more critical of her course for a number of reasons. She even considered leaving because of her 
treatment by one staff member, which left her feeling discouraged. Overcoming this has taken great personal resilience and support from her mother and partner. She also drew strength from being supportive of other students at the same time. Despite these drawbacks college has been a transitional space for Katy. She has excelled at her academic studies, she is considering a postgraduate degree and her course has bolstered her desire for a different and, in her view, more socially valuable form of work.

In discussing her learning story and her life story it is clear that Katy's decision to go to college was informed by a desire for recognition of her capability and to develop her abilities in a way that can contribute to the flourishing of others. It is apparent that the structural inequalities of gender and class in families, institutions and society play a significant part in the formation of learner identity. Renegotiating her learner identity in college has been a meaningful process which is underpinned by the logic of intersubjective recognition as it relates to both her private and public self. Katy has thrived in college mainly through her own resilience. In addition, her story indicates, we think, how pedagogical and other institutional practices, acknowledging or ignoring recognition needs, might be essential to human flourishing. Her ambition to play with the possibility of becoming a teacher confirms how becoming a valued and respected member of a community is a deeply experienced desire and identity building process.

\section{Conclusion}

We suggest that more nuanced understanding of the dynamic of why some students prosper in particular university sub-cultures and why some remain 'fish out of water' is required, beyond the strangely metaphysical language of 'les miracules' (Chapman Hoult, 2012). There are profound but insufficiently understood psychosocial dimensions to misrecognition but also to recognition and transformative processes in learning. We need to bring into the frame the dynamics of self-recognition, encompassing the intimate, mezzo as well as wider societal levels. At an intimate level, recognition has to do with experiences of selfhood, and of finding good enough space to play, without fear of rejection or of never being good enough. Sue and Katy learned to play agentically, which suggests a less determined, more malleable notion of habitus than is often implied. In fact, Honneth leads us to assert that equality, identity, autonomy, freedom and self-realisation can only be achieved intersubjectively, through a process of being recognised by significant others; initially as children, later as adults, but always with the child remaining in the adult too, in a rather more nuanced, less linear theory of subjectivity. The implication of this for teaching and education might be considerable - instead of foregrounding technique and teaching technologies, the most important issue could be the quality of human interaction and mutual recognition. In this way the well-recognised phrase 'the personal is political' becomes 'the political is personal.' Teaching is (or ought to be) an experience of mutual recognition, remembering that it has the potential to undermine selfhood and development. But it can create the conditions in which we can exist in the world more openly and spontaneously, despite anxieties, and feel seen and valued, however precariously. A self can simply be, 
and move to claim space for play and experiment unselfconsciously. However, Honneth, in his reworking of critical theory, broadens the focus beyond intimate relationships to the dynamics of recognition at institutional and social levels.

Such ideas have implications for teaching and learning in higher education, as well as for theorising experiences of universities (see Murphy and Brown, 2012). Though not new, a reemphasis on the relational aspect of the teaching/ learning transaction is overdue. However, deeper understanding of the social and political implications of such recognition and indeed the opposite, destructive dynamics of misrecognition and disrespect, might give a different emphasis to higher education. The added value for universities is to see that what is often reduced to a purely interpersonal transaction or, worse, a technical exchange (of information, or exchanges on e-learning platforms) potentially has profound social and political dynamics. This involves placing experiences of recognition at the heart of the educational project. It may help redefine the teacher-student relationship, too often reduced to overly individualistic terms. As a result, education - including higher education - has the possibility of becoming a locus for fostering and supporting social equality and facilitating the individual, interpersonal and social skills needed for a democratic egalitarian project. This offers the possibility and intellectual equipment required to both argue and act against the dominant market model so prevalent today in universities. Traditionally, psychoanalysis and the ways in which it was applied to education emphasised the importance of unconscious processes as well as the tendency to locate obstacles to learning as residing in the student. Now we can reclaim the better moments of psychoanalytic insight and locate problems (and solutions) in the interactive space created by teachers and institutions, in other words in relationships and context.

We straddle important disciplinary boundaries in the above process; connecting socio-cultural and psychological dimensions, in epiphanal experience. If Bourdieu helps us to understand how cultures become embodied in everyday practice and how a university habitus may inhibit those from particular backgrounds, Honneth and Winnicott illuminate how non-traditional learners may bring new capital into universities and, via good enough recognition, challenge and affect the habitus and claim space for self-confidence, self-respect and self-esteem; or, quite simply, become more fully and agentically themselves.

\section{References}

Bainbridge, A. and West, L. (eds.) (2012) Psychoanalysis and Education: Minding a Gap, London: Karnac.

Bourdieu, P. (1986) 'The forms of capital', in Richardson, J. G., Handbook for Theory and Research for the Sociology of Education, pp. 241-258, Westport, CN: Greenwood Press.

Bourdieu, P. (1988) Homo Academicus, Stanford, CN: Stanford University Press.

Bourdieu, P. (1990) In Other Words: Essays toward a Reflexive Sociology, Stanford, CN: Stanford University Press.

Bowles, S. and Gintis, H. (1976) Schooling in Capitalist America: Educational Reform and the Contradictions of Economic Life, New York: Basic Books. 
Brown, T. and Murphy, M. (2012) 'The dynamics of student identity: The threats from a neoliberal model and the benefits for a relational pedagogy', in West, L. and Bainbridge, A. (eds.), Psychoanalysis and Education: Minding the Gap, pp. 217-242, London: Karnak.

Chapman Hoult, E. (2012) Adult learning and La Recherche Féminine: Reading Resilience and Hélène Cixous, London: Palgrave Macmillan.

Charmaz, N. (2006) Constructing Grounded Theory: A Practical Guide through Qualitative Analysis, London: Sage.

Dirkx, J. M., Mezirow, J. and Cranton, P. (2006) 'Musings and reflections on the meaning, context and process of Transformative Learning', Journal of Transformative Education, vol. 4, pp. 123-139, Sage Publications.

Fleming, T. (2011) 'Recognition in the work of Axel Honneth: Implications for Transformative Learning Theory', in Alhadeff-Jones, M. and Kokkos, A. (eds.), Transformative Learning in Time of Crisis: Individual and Collective Challenges, pp. 95-101, New York: Teachers College, Columbia University.

Fraser, N. And Honneth, A. (2003) Redistribution or Recognition? A Political-philosophical Exchange, London: Verso.

Fuller, S. (2009) The Sociology of Intellectual Life: The Career of the Mind in and around Academy, London: Sage.

Glaser, B. G. and Strauss, A. L. (1967) The Discovery of Grounded Theory: Strategies for Qualitative Research, Hawthorne, NY: Aldine.

Honneth, A. (1995a) The Struggle for Recognition: The Moral Grammar of Social Conflicts, Cambridge: Polity Press.

Honneth, A. (1995b) The Fragmented World of the Social: Essays in Social and Political Philosophy, New York: SUNY Press.

Honneth, A. (2007) Disrespect: The Normative Foundations of Critical Theory, Cambridge: Polity Press.

Honneth, A. (2009) Pathologies of Reason: On the Legacy of Critical Theory, New York: Columbia University Press.

Huttunen, R. (2008) Habermas, Honneth and Education: The Significance of Jürgen Habermas's and Axel Honneth's Critical Theories to Education, Cologne: Lambert Academic Publishing.

Illeris, K. (2002) The Three Dimensions of Learning, Malabar, FL: Krieger.

Merrill, B. and West, L. (2009) Using Biographical Methods in Social Research, London: Sage.

Mezirow, J. and associates (2000) Learning as Transformation: Critical Perspectives on a Theory in Progress, San Francisco: Jossey-Bass.

Murphy, M. and Brown, T. (2012) 'Learning as relational: Intersubjectivity and pedagogy in higher education', International Journal of Lifelong Education, 31(5), pp. 643-654, Taylor \& Francis.

Murphy, M. \& Fleming, T. (2013) 'Between common and college knowledge: Exploring the boundaries between adult and higher education', in Murphy, M. (ed.), Social Theory and Education Research (Vol. 1 Inequality, Inclusion and Education), London: Sage.

RANLHE (2011) Retention and Access of Non-traditional Students in Higher Education, www.dsw.edu.pl/fileadmin/www-ranlhe/index.html

Reay, D., David, M. and Ball, S. (2005) Degrees of Choice: Social Class, Race and Gender in Higher Education, Stoke-on-Trent: Trentham.

Sclater, S. D. (2004) 'What is the subject?' Narrative Enquiry, 13(2), pp. 317-330.

Sinclair, S. (1997) Making Doctors, Oxford: Berg.

West, L. (1996) Beyond Fragments: Adults, Motivation and Higher Education, London: Taylor \& Francis.

West, L. (2009) 'Lifelong learning and the family: An auto/biographical imagination', in Jarvis, P. (ed.), The Routledge International Handbook of Lifelong Learning, pp. 67-69, London: Routledge. 
West, L. (2011a) 'Crises, ambivalence and ambiguity in transformative learning: challenging perspectives from auto/biographical narrative research', Paper to the Ninth International Conference on Transformative Learning, Athens.

West, L. (2011b) 'Family disputes: Science, poetry and subjectivity in biographical narrative research', in Herzberg H. and Kammler, E. (eds.), Biographie und Gelleschaft, pp. 415-434, Frankfurt: Campus Verlag.

Winnicott, D. (1971) Playing and Reality, London: Routledge. 
Copyright of Studies in the Education of Adults is the property of National Institute of Adult Continuing Education and its content may not be copied or emailed to multiple sites or posted to a listserv without the copyright holder's express written permission. However, users may print, download, or email articles for individual use. 